\title{
Evaluation of the Natural Landscape Aesthetic: a Case Study of Uvs Province, Mongolia
}

\author{
Narankhuu Erdenejargal $^{1}$, Batsuren Dorjsuren ${ }^{2 *}$, Lkhagvasuren Choijinjav ${ }^{1}$, \\ Dash Doljin ${ }^{3}$, Altanbold Enkhbold ${ }^{4}$, Bilegsaikhan Munkhuu ${ }^{5}$, \\ Boldbaatar Natsagdorj ${ }^{6}$, Abel Girma ${ }^{7}$
}

${ }^{1}$ Department of Geography and Geology, School of Natural Science and Technology, Khovd State University, Khovd 164300, Mongolia

${ }^{2}$ Department of Environment and Forest Engineering, School of Engineering and Applied Sciences,

National University of Mongolia, Ulaanbaatar 210646, Mongolia

${ }^{3}$ Department of Geography, School of Mathematics and Natural Sciences, Mongolian National University of Education, Ulaanbaatar 210648, Mongolia

${ }^{4}$ Department of Geography, School of Art \& Sciences, National University of Mongolia, Ulaanbaatar 210646, Mongolia ${ }^{5}$ Department of Commerce and Marketing, National University Commerce and Business, Ulaanbaatar 210646, Mongolia ${ }^{6}$ Division of GIS and Cartography Institute of Geography and Geoecology, Mongolian Academy of Sciences (MAS), Ulaanbaatar-15170, Mongolia

${ }^{7}$ College of Environmental Science and Engineering, Donghua University, Shanghai, 201620, China

Received: 28 November 2020

Accepted: 25 January 2021

\begin{abstract}
Natural landscape aesthetic is the natural resource that is essential for maintaining mental and physical health of humans. Therefore, a natural landscape is the source of human life. The aim of this study was to assess the natural landscape aesthetic of Uvs province, Mongolia, using a combination of the spatial multi-criteria decision-making method (MCDM) and the analytic hierarchy process (AHP) based on Boolean and fuzzy logic. Ten different criteria were used for the analysis. We developed the aesthetic landscape assessment tier for Uvs province to evaluate each natural beauty indicator in five stages. The result shows that $13.2 \%$ of the area of Uvs province was highly suitable, $39.4 \%$ was suitable, and $46.7 \%$ was unsuitable for recreational purposes. The landscape aesthetic potential of Uvs province was mapped. The landscape aesthetic assessment for recreational purposes is possible using GIS and remote sensing technology based on a combination of the multi-criteria decision output and the proposed matrix. Future work should focus on other regions of Mongolia. The developed method of landscape aesthetic evaluation for recreational purposes can be used in land management.
\end{abstract}

Keywords: tourism, landscape aesthetic, scenic beauty, recreational

*e-mail: batsuren@seas.num.edu.mn 


\section{Introduction}

Landscape study is very significant for examining the relationship between nature and humans. The landscape is a complex of terrestrial water and the land surface formed by various origins, with features of ecosystems. The landscape contains many variable meanings that have not yet been agreed upon $[1,2]$. There are various definitions of landscape [3-5]. Taken together, these definitions are that landscapes are a complex combination of all geofactors in a particular space or area in a part of the world [6]. A natural landscape is the combination of genetic parts of the same topography of a given area, such as rocks, topography, climate, groundwater and surface water, soil, plant, and animal species [7-10]. In order to solve the socioeconomic problems of the territory and the country, it is important to correctly identify them in terms of the type of landscape, features, and use as a resource for tourism and recreation [11]. At present, the relationship between nature and society is marked by the strengthening development of the tourism industry. This tendency is observed in many countries, and nowadays, tourism brings many trillions of dollars in revenue globally $[12,13]$. New lands and territories are being allocated for recreational activities, and many people are being involved in recreational use of nature. The natural object most commonly used for recreational purposes is the geographical landscape [14]. The landscape has many properties that are directly reflected in the recreational environs, and one of them is aesthetic attractiveness [15]. Geographic research in landscape aesthetics seeks to solve the issues of selecting sites that are most suitable for recreational facilities [16]. In this respect, territory planning should be based on the evaluation that takes into account all aspects of landscape quality. Mongolia's landscape is characterized by a relatively highland area dominated by arid steppes and deserts, with very little continental rainfall. Mongolia is located in the middle zone of the gradual transition from the dry steppes of Central Asia to the Great Siberian Forest and Taiga. Mongolian territory is the northern cold humid climate to the southern very dry climate $[17,18]$. It coexists with the Siberian landscape and the Central Asian desert landscape [17]. This situation is a great test for depression. Following the high mountains, the Siberian landscape pushes forward, while the steppes follow the lowlands, and the Central Asian desert landscape extends to the north, reaching the slopes, peaks, and balconies [19].

Lee-Hsueh [20] states that 'scenic aesthetic is the outcome of interactions between humans and landscapes'. People tend to appreciate and enjoy scenic views and good environment that arouse positive emotions. Landscape aesthetic and ecological quality can overlap in some aspects. For instance, the visual variety of the landscape can be generated by natural design and correlated to the incidence of biological productive effects. Thus, the aesthetic experience, lived in positive emotions, meet the advantages of ecological experience [21].

In this paper, we focus on the assessment of natural landscape aesthetics. The aim of this study was to evaluate the natural landscape aesthetics of Uvs province, Mongolia, using a combination of the spatial multi-criteria decision making-method (MCDM) and the analytic hierarchy process (AHP) based on Boolean and fuzzy logic.

\section{Material and Methods}

\section{Study Area}

Uvs province is located in the northwestern part of Mongolia, sharing a $575 \mathrm{~km}$ border with the Republic of Tuva (Russian Federation) in the north, a $200 \mathrm{~km}$ border with Bayan-Ulgii province, a $152 \mathrm{~km}$ border with Khovd province in the south, and a $340 \mathrm{~km}$ border with Zavkhan province in the east (Fig. 1).

The province has the high mountains of Khan Khooloi and Togtokiin Shil, the Khan Khukhii mountain range, the Kharkhiraa, Turgen and Tagna mountain ranges stretching from the Mongolian Altai mountainous region, alpine tundra, forest taiga, mountain steppe, a part of the Gobi desert, steppes, and desert elevation. Uvs Lake depression is represented $\mathrm{s}$ the northernmost part of the Gobi desert. The conditions of this Gobi desert made the region unique in terms of landscape [22].

The territory of Uvs province is rather varied since it is located at the intersection of three major geographical regions that are quite distinct from each other. The western part of the province is covered by the Kharkhiraa-Turgen Mountains that belong to the Great Altai mountainous region; its eastern part is covered by the Khan-Khokhii Mountains that belong to the Khangai region; and its southern and northern parts are occupied by the hollows of Uvs and Khyargas lakes of the depression of the Great Lakes depression [23]. Due to these specific features, the landscape division is governed by the system of mountains and depressions with high, medium-high, and low mountains and intermountain depressions.

\section{Methodology}

This study applies a combination of Boolean and fuzzy logic, the spatial multi-criteria decision-making method (MCDM), and the analytical hierarchical process (AHP) (Fig. 2). The general procedure for landscape aesthetic assessment had several stages:

1. define the objective,

2. select the criteria, for which there are two kinds of factors and constraints,

3. standardize the criteria,

4. assess the ranking and the weight of the criteria,

5. superpose the map layers. 


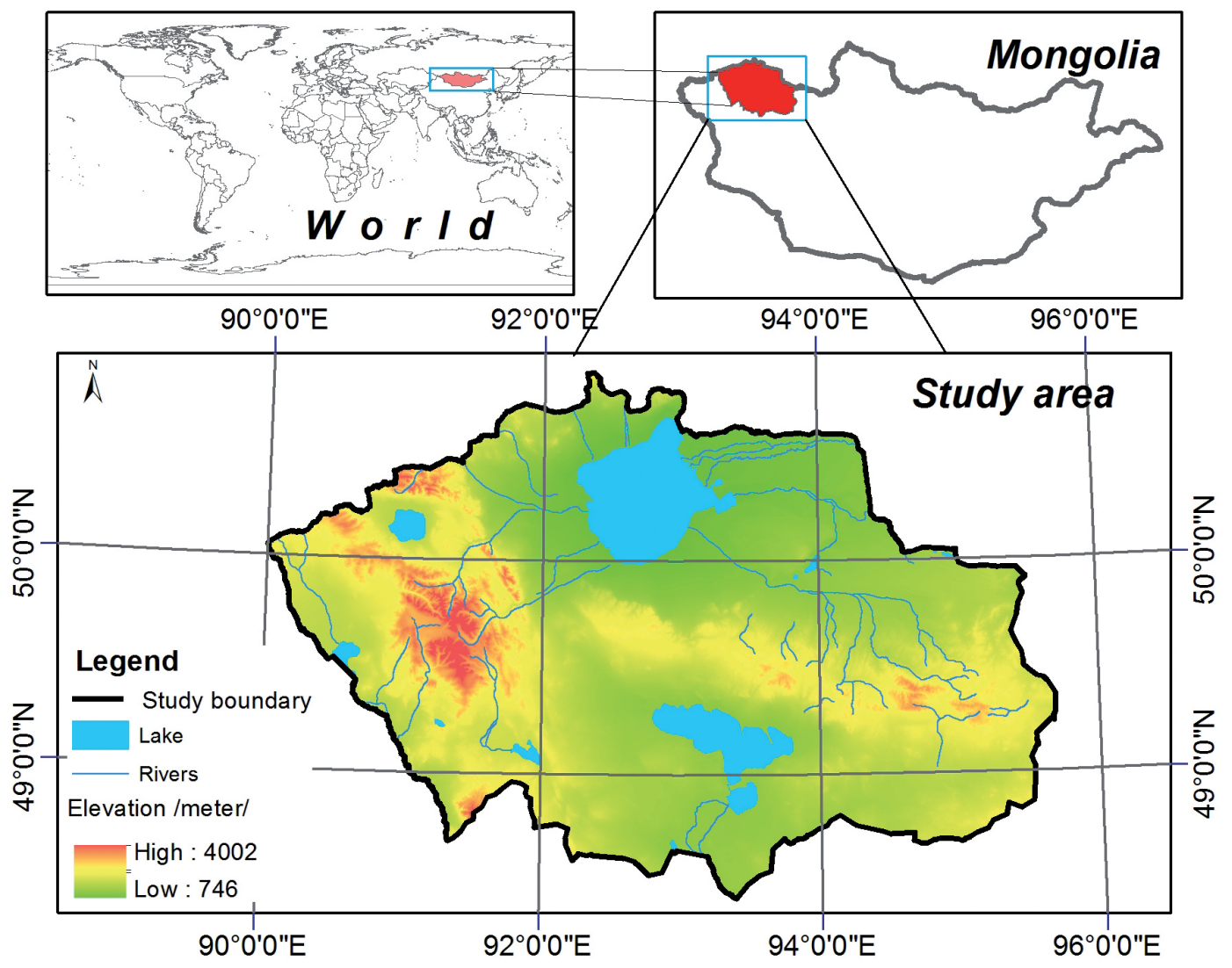

Fig. 1. Location of Uvs province.

\section{Constraint Map Creation}

The constraint map was generated using Boolean logic. Constraints can be expressed in the form of a Boolean (logical). Boolean logic can have only two outcomes, true (1) or false (0). A constraint factor is a discrete metric that can represent a true or false condition. Zero values are prohibited conditions, and 1 values are permitted conditions. Constraints in this particular study often included legal restrictions. These were current land-use policy restrictions. Condition assessments and prohibitions can be factors as well [24].

\section{Factor Map Creation}

A factor is a criterion that can determine the suitability of specific outcomes for activities under consideration [25]. The spatial MCDM method was used in the creation of factor maps. Suitability levels for each of the factors were defined; these levels were used as a base to generate the factor maps one for each factor [26]. Evaluating natural landscapes scenically and aesthetically was expressed by qualitative and quantitative parameters.

\section{Criteria Standardization}

All criteria used in the analysis were measured with different measurement values. Different criteria values needed to be transformed into common values [27]. In this study, a simple linear scaling equation based on the fuzzy set method was used:

$$
E_{i}=\frac{X_{i}-X_{\min }}{X_{\max }-X_{\min }}
$$

...where $E_{i}$ the value of is standardized in pixels $i, X_{\min }$ is the minimum value, and $X_{\max }$ is the maximum value.

\section{Assessing Criteria Ranking and Weights}

In the last two decades, three methods have been widely used to define multi-criteria evaluation: Analytic Hierarchy Process (AHP), the Ideal Vector Approach, and Fuzzy AHP. In this study, the AHP approach was used to find a weighted value of criteria. AHP is one of the most commonly applied approaches in decision-making [28] because it is useful for multiple parameters ranked according to experts' preferences $[24,29,30]$. Tomas Saaty developed it in 1977. AHP is focused on the principles of decomposition, comparative judgment, and synthesis of priorities [31]. AHP considers the context of spatial planning decisions, and identifies and arranges criteria into different groups [32]. AHP was calculated by weighted values of the criteria, and it can be expressed with the following equation: 


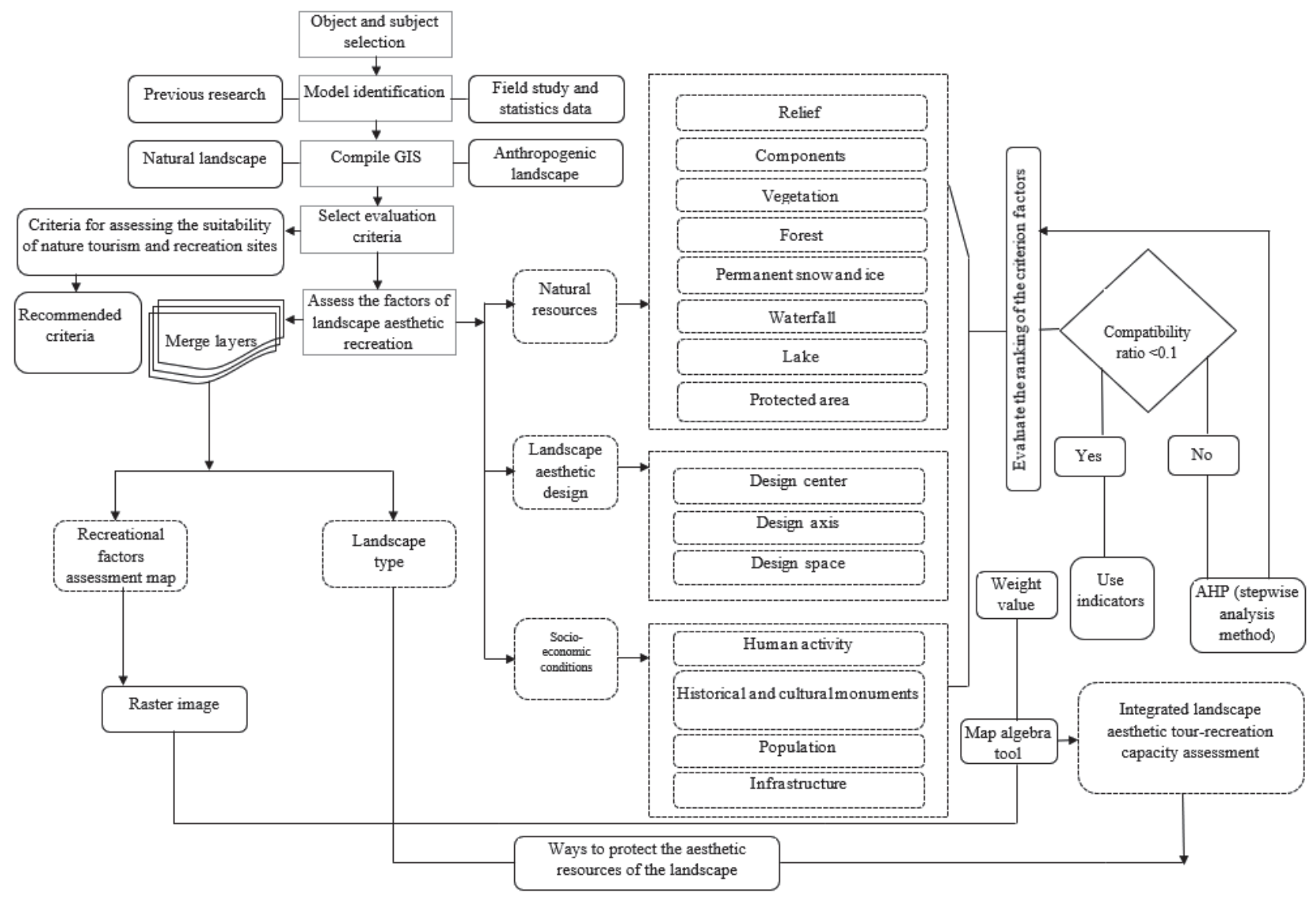

Fig. 2. Research methodical scheme.

$$
W_{i j}=\frac{\sum X(i j)}{n}
$$

...where $X_{i j}$ is the normalized value of a pairwise comparison matrix, $n$ is the order of the matrix, and $W_{i j}$ is the weight of the criteria. The consistency ratio indicates the probability, and that the matrix ratings were randomly generated [24]. The consistency of the pairwise comparison matrix is expressed by the consistency index. When the consistency ratio exceeds 0.1 , the weighted value is disagreeable, and when the index value is estimated below 0.1, the weighted value is agreeable:

$$
C R=\frac{C I}{R I}
$$

...where $C I$ is the consistency index, $R I$ is the random index, and $C R$ is the consistency ratio. The consistency index was calculated using the following equation:

$$
C I=\frac{\lambda_{\max }-n}{n-1}
$$

...where $C I$ is the consistency index, $\lambda_{\max }$ is the maximum eigenvalue, and $n$ is the order of the matrix.

\section{Superposing Map Layers}

After describing the values of the weighted criteria concerning their importance for landscape analysis, all criteria maps were overlaid using the suitability index. The formula used for calculating the suitability index of each layer was as follows:

$$
S_{i}=\sum \mathrm{Xi} * \mathrm{Wi}
$$

...where $X i$ stands for the values of each criterion, $W i$ stands for the weighted values of each criterion, and $S i$ is the suitability index.

\section{Criteria Selection}

Several authors have evaluated landscape aesthetic and natural beauty of mountainous areas. Dirin [33] has developed a methodology for assessing landscape aesthetic and scenic beauty for the Ust-Koksinsk region of the Altai Republic, Russia, and has used the following ten criteria:

1. Density of boundaries between visually identifiable natural features $\left(\mathrm{m} / \mathrm{km}^{2}\right)$. A combination of natural terrain features or scenes that are visually attractive and distinguishable in the landscape typology, makes 
the area more scenic and picturesque. The level or the range of aesthetic appeal can be evaluated by the combination of the elements that create these natural features or scenes, the coverage area of this combination, and its frequencies.

2. Diversity of the constituent elements. The geographical landscape consists of a variety of elements. They can be classified into four groups: geology-geomorphologic, hydrological, glacial, and biological. The geology-geomorphological group includes rocks, stones, exposures of bedrocks, moraines, talus cones, rock debris, and pebbles. The hydrological group includes water objects that spread over the definite area (lakes and pools), and flowing watercourses (rivers, brooks, springs, and wells). The glacial group includes glaciers, perpetual snow, and fluvio-glacial plains. The biological group includes needle-leaved (or soft-wood) and deciduous forest, shrubs, half-shrubs, herbaceous plants, and lichens.

3. Color palette. An important and measurable criterion of landscape aesthetic is the color palette that the vegetation cover gives to the landscape. Humans sense and perceive vigilantly not only shapes but also colors. Natural scenes benefit from colorful speckles and sequences.

4. Composition nodes. General value and harmony determine the composition of natural beauty on the perceptible level. A criterion for landscape aesthetics is the availability of composition nodes in the grandeur of nature. It may seem good to have as many composition nodes of natural beauty as possible, but the reasonable number is four to five. They create a memorable aesthetic effect.

5. Composition axes. In natural aesthetic, the significance of the main contour of the scene is very high. Linear objects that permeate through the natural landscape form the axes of the composition. The axes and the nodes of the composition attract an observers' attention.

6. Availability of scene sides. The enigmatic beauty of nature is explored within the framework of the objects as human-made green infrastructure and plants, or the types of relief as mountains, steppes, basins, and non-regional valleys. When enigmatic beauty circumscribes the grandeur of nature from both sides, the attractiveness of landscape is created. The scene side highlight the grandeur of nature.

7. Depth and diversity of visual perspective. In many aspects, the attractiveness of a landscape depends on the depth of open vista from a specific point of observation or, in other words, the broadness of the space that is being looked at. The perspective can be close, intermediate and remote, and when all the three types exist in the scenery from the same point of observation, the beauty of the landscape is the most apparent.

8. Forest coverage (forest's role in scenic beauty). Many researchers have emphasized that forest coverage of the landscape plays an important aesthetic role.
When people think of travelling through a beautiful landscape, they mostly imagine a forest as healthy and pleasant scenery. Therefore, the forest factors must be a criterion of in the natural aesthetic assessment methodology [34].

9. Symbolic natural objects. The presence of extraordinary, rare natural and socio-cultural objects is very significant for the attractiveness of a landscape. Researchers name such objects as "symbolic" because they make the grandeur of nature more specific and distinctive.

10. Anthropogenic transformation of the landscape. The most important factor that influences the attractiveness of landscape aesthetic is the level of changes that were caused by human activities. Human acts in natural environs are captured in the visage of nature.

Every landscape has its own aesthetic and natural beauty, and the above-mentioned criteria such as landscape diversity, color palette, composition, symbolic objects, anthropogenic transformation and others, increase the landscape attractiveness. In other words, it considerably depends upon the types of reliefs, which is the main factor that constitutes landscapes, and Uvs province with the combined territory of mountains and hollows has relatively good landscape attractiveness [35].

Landscape diversity is influenced by many factors such as nature-climatic zone, distance from seas and oceans, elevation zoning, location of mountains and mountain ranges, adjacent exposure, steepness, sculptural reliefs and intensity of modern physical and geographic processes [36, 37]. Landscape color accord most increases the beauty of nature, and it is understood as an agglomeration of various types of landscape in a relatively small area. Landscape distinctiveness or singularity influences humans favorably depending on the presence of aboriginal and rare species areal, and confinements from the neighboring area. Owing to the abundance of natural, historic, and cultural symbolic objects in the landscape, the aesthetic value of the landscape ascends, and here, natural objects include waterfalls, lakes, karst caves, tunnels, and other geomorphologic forms.

Using the above-mentioned criteria for assessing landscape aesthetic and scenery, we attempted to assess landscape types of the Uvs province of Mongolia. To do that, we enriched the point scales for criteria developed by Dirin with the methodology processed by other researchers [33]. The principle of this methodology is to assess every criterion of landscape aesthetics and scenery by three-score scale (1-3 score) and their integrated assessment is divided into 3 classes (Tables $1-2)$.

\section{Data Analysis}

The territory of Uvs province is rather varied, since it is located at the intersection of three major 
Table 1. Criteria for landscape aesthetic assessment.

\begin{tabular}{|c|c|c|c|}
\hline Criteria & Acronym & Numeric meaning of criteria & Score \\
\hline \multirow{7}{*}{$\begin{array}{l}\text { Density of boundaries between } \\
\text { visually identifiable natural features } \\
\qquad\left(\mathrm{m} / \mathrm{km}^{2}\right)\end{array}$} & \multirow{7}{*}{$\mathrm{C} 1$} & 0 & 0 \\
\hline & & $0.1-1.5$ & 1 \\
\hline & & $1.6-3.0$ & 2 \\
\hline & & $3.1-4.0$ & 3 \\
\hline & & $4.1-5.5$ & 2 \\
\hline & & $5.6-7.0$ & 1 \\
\hline & & $>7$ & 0 \\
\hline \multirow{5}{*}{ Diversity of the constituent elements } & \multirow{5}{*}{$\mathrm{C} 2$} & $1-2$ elements & 1 \\
\hline & & $3-4$, dominantly $1-2$ & 2 \\
\hline & & $5-7$, dominantly $3-4$ & 3 \\
\hline & & $>7$, dominantly $3-4$ & 2 \\
\hline & & $>7$ alone & 1 \\
\hline \multirow{4}{*}{ Color palette } & \multirow{4}{*}{$\mathrm{C} 3$} & Black, charcoal grey & 0 \\
\hline & & Almond, brown & 1 \\
\hline & & Dark blue, green & 2 \\
\hline & & Yellow-red, white, pink, light blue & 3 \\
\hline \multirow{7}{*}{ Composition nodes } & \multirow{7}{*}{$\mathrm{C} 4$} & None & 0 \\
\hline & & 1 & 1 \\
\hline & & 2 & 2 \\
\hline & & 3 & 3 \\
\hline & & 4 & 2 \\
\hline & & 5 & 1 \\
\hline & & $>5$ & 0 \\
\hline \multirow{3}{*}{ Composition axes } & \multirow{3}{*}{$\mathrm{C} 5$} & No axis & 0 \\
\hline & & One axis & 1 \\
\hline & & Several axes & 2 \\
\hline \multirow{3}{*}{ Availability of scene sides } & \multirow{3}{*}{ C6 } & None & 0 \\
\hline & & From one side & 1 \\
\hline & & From two sides & 2 \\
\hline \multirow{4}{*}{$\begin{array}{l}\text { Depth and diversity of visual per- } \\
\text { spective }\end{array}$} & \multirow{4}{*}{$\mathrm{C} 7$} & Close & 0 \\
\hline & & Close and intermediate & 1 \\
\hline & & Close, intermediate and remote & 2 \\
\hline & & Close and remote & 1 \\
\hline \multirow{6}{*}{ Forest coverage (in \%) } & \multirow{6}{*}{$\mathrm{C} 8$} & 0 & 0 \\
\hline & & $1-15$ & 1 \\
\hline & & $16-30$ & 2 \\
\hline & & $31-60$ & 3 \\
\hline & & $61-85$ & 2 \\
\hline & & $>85$ & 1 \\
\hline \multirow{3}{*}{ Symbolic natural objects } & \multirow{3}{*}{ C9 } & $\begin{array}{l}\text { Perpetual snow, glaciers (distance in meters }<500 \text {; } \\
\qquad 500-2000 ;>2000)\end{array}$ & $3 / 2 / 1$ \\
\hline & & Lakes (distance in meters $20-500 ; 500-2000 ;>2000$ ) & $3 / 2 / 1$ \\
\hline & & $\begin{array}{l}\text { Waterfalls (distance in meters } \\
10-100 ; 100-500 ;>500\end{array}$ & $3 / 2 / 1$ \\
\hline
\end{tabular}


Table 1. Continued.

\begin{tabular}{|c|c|c|c|}
\hline \multirow{4}{*}{$\begin{array}{c}\text { Anthropogenic transformation of the } \\
\text { landscape }\end{array}$} & \multirow{2}{*}{$\begin{array}{c}* \\
\text { C10 }\end{array}$} & No transformation & 3 \\
\cline { 3 - 3 } & & Measonoble transformations & 2 \\
\cline { 3 - 4 } & & Eroded landscape & 2 \\
\cline { 3 - 4 } & & 3 & 3 \\
\hline
\end{tabular}

Table 2. Scale of points for landscape aesthetic assessment.

\begin{tabular}{|c|c|c|c|}
\hline Assessment scale & Categories of aesthetic assessment & Total score & Rates and coefficients of aesthetic assessment \\
\hline I & Much higher assessment of natural beauty & $>22$ & $85-100(0.78-1.0)$ \\
\hline II & High assessment of natural beauty & $18-22$ & $67-84(0.64-0.7)$ \\
\hline III & Medium assessment of natural beauty & $13-17$ & $48-66(0.46-0.64)$ \\
\hline IV & Low assessment of natural beauty & $8-12$ & $30-47(0.28-0.46)$ \\
\hline V & Much lower assessment of natural beauty & $<8$ & $<30(<0.2)$ \\
\hline
\end{tabular}

geographical regions that are quite distinct from each other. The western part of the province is covered by the Kharkhiraa-Turgen Mountains that belong to the Great Altai mountainous region; its eastern part is covered by the Khan-Khokhii Mountains that belong to the Khangai region; and its southern and northern parts are occupied by the hollows of Uvs and Khyargal lakes of the depression of the Great Lake. Due to these specific features, the landscape division is governed by the system of mountains and depressions with high, medium-high and low mountains and intermountain depressions.

The Kharkhiraa-Turgen Mountains, located in the western part of the territory, are atmospherically continental and have rather good fluvial nets, and continuous and interrupted spread of long-lasting critics. Almost all of its mountains are elevated relatively higher compared with other regions. Therefore, the area is dominated by not only mountainous meadow landscape with the frozen-dry pattern, which was formed in the natural conditions similar to the Ice Age, but also high-mountainous steppe landscape with cushion forbs-fescue vegetation with steppe coarse humus soil and the landscape of bald and high mountains with perpetual snow and ice. The traces that the mountains in the area iced much during the Quaternary period are seen here, especially in the western part. Due to glaciations, corries were formed in the higher layers of the mountains, and their downhill became steep and hollow by being eroded by river valleys and glaciers. Besides, there are accumulations of lodge moraines on their bottoms and sides [38].

The Khan-Khukhii Mountains, the most western branch of the Khangai mountain ranges, are deeply ingressive to the central part of the area and located at the intersection of Uvs and Khyargas lakes of the Great Lakes depression. The Khan Khokhii Mountains are lower than the Khangai mountain ranges, and its highest peak is 2928 meters in its eastern section. To the western part, an absolute altitude of the surface becomes lower to the Togtokh massif, whose peak Khurmen-ovoo is 2,356 meters. The vertical zonality of the landscape is revealed in the Khan Khokhii Mountains. The highest peak belongs to the landscape of bare talus, stony slopes, and high peaks. Lowering from the peak, it has landscapes of the flat surface of mountain heads, mountain meadow, and meadow steppe. The landscapes of dry steppe and desert-like steppe dominate on the steep slopes of the front side of the mountain, whereas taiga, forestall, forest-steppe, steppe and dry steppe landscapes spread on the inclined slopes of the mountainside.

The depression of Uvs Lake spread on the northern part of the territory of this province is located on the north part of the tectonic hollow called Great Lakes depression, which stretches along the longitude by separating Altai and Khangai Mountains in the deep basin among Central Asian mountain ranges. The water-level of Uvs Lake located in the center of Uvs Lakes depression is 759 meters above sea level, and it is the lowest among the other parts of the Great Lakes depression. Since the Uvs Lake depression is located at the lowest northern part of the Great Lakes depression, its landscape, and geographic location are peculiar. Here, the Uvs Lake itself covers a relatively large area and the complex of sand accumulations, potash, salt marsh and swamp encircling the lake also covers a large area. From the bed of the hollow to the foot of the mountain, there are several types of landscapes with regional peculiarities. We mapped the landscape with a resolution of $10 \mathrm{~km}$ that shows these peculiarities of Uvs province, and it classified 28 types of landscapes in 16 typologies that represent mountains and relief landscapes [39] (Fig. 3).

In this map, it can be seen that the hollows that encircle Uvs, Khyargas, Achit, Uureg, Namir, and Khar Us lakes have desert-like steppe and semidesert landscapes. There is vertical zonality on 


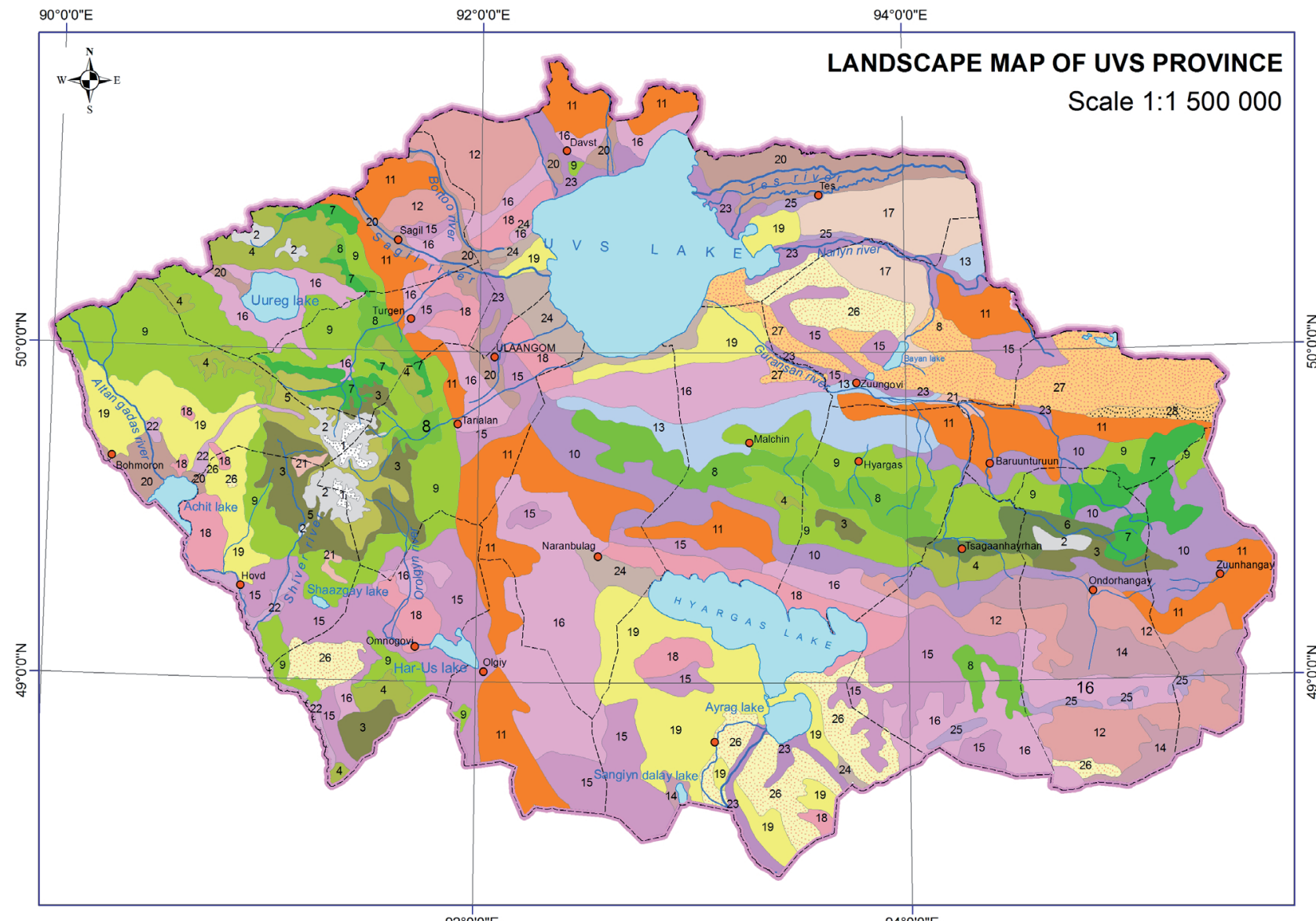

$92^{\circ} 0^{\prime} 0 " \mathrm{E}$

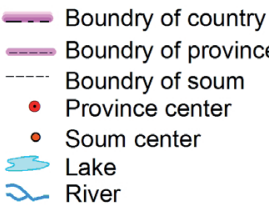

LEGEND

I. LANDSCAPE OF HIGH MOUNTAINOUS

ACCUMULATED SNOW AND ICE

1 Accumulated snow and ice on the highest peaks and ridges of mountains

II. LANDSCAPES OF MOUNTAIN WITH A GLACIER

OR COVERED WITH SNOW AND ICE

2 High mountainous glacier with snow and ice located lower than accumulated snow

III. LANDSCAPES OF HIGH MOUNTAINOUS MEADOW

3 High mountain meadow with the vegetation of sedges-forbsingreensward brown soil onflat surfaces and ridges of mountain tops

IV. LANDSCAPES OF HIGH MOUNTAINOUS MEADOW STEPPE

4 High mountain meadow steppe with the vegetation of tussocks grasses-forb in meadow steppe brown soil on flat surfaces and ridges of mountain tops

V. LANDSCAPES OF HIGH MOUNTAINOUS STEPPE

5 High mountain steppe with the vegetation of grasses-forbs in high mountain steppe dark brown soil on flat surfaces and ridges of mountain tops

VI. LANDSCAPES OF MOUNTAINOUS TAIGA

Forest /Northern taiga/ with the vegetation of green moss, shrubs-green

6 moss, larch-cedar and cedar-larch forest in permafrost taiga and ash-like soil on flat surfaces and ridges of 1800-2000 meter high mountains VII.LANDSCAPE OF MOUNTAINSIDE FOREST

7 /Southern taiga/ Larch forest with dry moss in forest permafrost coarse soil on mountain tops and slopes

VIII.LANDSCAPE OF MOUNTAINOUS FOREST STEPPE

Interchanges of meadow steppes with the vegetation of larch, pine,

8 pine-larch forests in lawn andsandy soil of mountainous forest and meadow steppe with the vegetation of various grasses,sedges-grasses in meadow dark brown and dark brown earth soil of mountainous forest IX.LANDSCAPE OF DRY STEPPE

9 Dry ridges of average medium high mountains

10 Arctic dry steppe of medium high mountains with shred and low mountains with less shred

11 Antarctic dry steppe of hill-like mounds with less shred $94^{\circ} 0^{\prime} \mathrm{O}^{\mathrm{E} E}$

2 Antarctic dry steppe with shreds and steep slope mountainside surface

13 Antarctic dry steppe with shreds and slope steppe-like surface

14 Antarctic dry steppe with less shred and slope-like steppe-like surface

X.LANDSCAPE OF DESERT-LIKE STEPPE Desert-like steppe with the vegetation of tussocks grasses-

15 weeds-stipe in mountainous thin surfaced bright brown soil with medium size slope surface of hill-like mounds with shred Desert-like steppe with the vegetation of semi-shrubs-

16 grasses-cleistogenes in bright brown soil with slope steppe-like surfaces and Deluvi-Propuvi slope steppe shred Desert-like steppe with the vegetation of grassy stipe including

17 various sandy and over-sandy grasses in bright brown soil without shred and with flat steppe-like surface

18 Desert-like steppe of medium high mountains

XI.LANDSCAPES OF SEMI-DESERT

19 Semi-desert with the vegetation of grasses in desert-like steppe brown soil without shred and with flat steppe-like surface B. REGIONAL LANDSCAPES

XII.LANDSCAPE OF FLOODPLAIN MEADOW Swampy meadow with the vegetation of couch-sedge-grasses

20 in meadow swamp permafrost soil along river mouths and lake banks

21 Meadow with the vegetation of grass-various grasses, various grasses-grasses in floodplain meadow soil

22 Thicket with the vegetation of asp and wicker-weed in floodplain meadow swampy soil Saline meadow with the vegetation of lawn-sedge and sedge,

23 grasses-ledge in meadow and meadow less-developed soil along river mouths

XIII.LANDSCAPE WITH SALT-MARSH

24 Community of couch, couch-broom grass including saltwort in meadow salt-marsh soil along lake banks Community of saltwort-wormwood including grasses in less salty soil

XIV.LANDSCAPE OF SAND ACCUMULATION Low hillock sand with the vegetation of tussocks

26 grasses-stipe in sandy brown soil

27 Hillock with the vegetation of weed-stipe with sand-dune

28. Hillock with the vegetation of sandy wormwood and tussock grasses /larches on the south of the sand/

Fig. 3. Main types of landscape. 
Table 3. Main types of landscape.

\begin{tabular}{|c|c|c|c|}
\hline \multirow{2}{*}{ Type } & \multirow{2}{*}{ Tssessment scale } & \multicolumn{2}{|c|}{ Total area } \\
\cline { 2 - 4 } & & $\mathrm{km}^{2}$ & 0.2 \\
\hline Accumulated snow and ice & II & 101.9 & 0.6 \\
\hline Mountain with a glacier or covered with snow and ice & III & 399.8 & 3.2 \\
\hline High mountain meadow & I & $2,047.3$ & 2.2 \\
\hline Meadow steppe & II & $1,419.6$ & 0.8 \\
\hline Mountain steppe & III & 545.7 & 0.7 \\
\hline Mountain taiga & II & 493.4 & 3.5 \\
\hline Mountainside forest & II & $2,225.3$ & 4.1 \\
\hline Forest steppe & II & $2,626.1$ & 10.9 \\
\hline Arctic dry steppe & III & $6,986.4$ & 5.1 \\
\hline Antarctic dry steppe & IV & $3,267.1$ & 16.9 \\
\hline Desert-like steppe & IV & $10,850.4$ & 27.9 \\
\hline Semi-desert & V & $17,893.9$ & 7.6 \\
\hline Floodplain meadow & V III & $4,880.9$ & 6.6 \\
\hline Complex of potash and salt marsh & V & $1,291.6$ & 2.0 \\
\hline Sand accumulation & IV & $4,943.1$ & 7.7 \\
\hline
\end{tabular}

Kharkhiraa, Turgen, Tsagaan Shuvuut, and Khan Khukhii mountains and gradually there are forest and taiga landscapes on the definite areal of mountainsides. The highest peak of Uvs province territory is 4,126 meters above sea level on Kharkhiraa, Turgen Mountains, and the lowest point is 758 meters above sea level in Uvs Lake depression. It creates a diversity of landscapes in the territory. According to the number of coverage areas of the landscapes in the territory of the province, $55.7 \%$ or $35,730.7 \mathrm{~km}^{2}$ of Uvs province territory has three types of landscapes: desert-like steppe, southern dry steppe, and mountainous dry steppe. The followings are the landscapes of semi-desert and sand accumulation and the least areas are covered by the landscapes of high mountainous accumulated snow and ice and mountainous taiga. When the territory of Uvs province was assessed by the above criteria with point scales, its mountainous areas had higher points, and lower areas had relatively low points (Table 3).

Table 3 shows that the landscapes of high mountain meadow, accumulated snow and ice, meadow steppe, mountain taiga, mountainside forest, and forest-steppe have the highest points. The landscapes of glacierized mountain, mountain steppe and floodplain meadow have the neutral points. The landscapes of Arctic and Antarctic dry steppes and sand accumulation have mountain steppe relatively low points. The landscapes of desert-like steppe, semi-desert, and complex of potash and salt marsh have the lowest points.

\section{Results and Discussion}

There are many reasons for carrying out tourism activities, such as protecting aesthetic resources of the territory, and appropriately identifying the outlook by conducting external and internal environment analysis for activities in tourism industry, and also considering its advantages and disadvantages.

In this study, ten criteria were applied for landscape aesthetic evaluation. The ranking of these criteria was based on a literature review and expert consultations, with the weights calculated using AHP based GIS (Table 4). We estimated a consistency ratio of 0.005 , suggesting that there was a reasonable level of consistency in the judgment (Table 5).

The result shows that the most important criteria were topographic, vegetation cover, protected area, and forest. In contrast, the least important criteria were monuments of historical and archaeological sites, infrastructure, and number of population.

After weighing the importance of different criteria for landscape aesthetic analysis, ten obtained maps were overlaid using the suitability index in ArcGIS. The research results show that $13.2 \%$ of the area of Uvs province of Mongolia was highly suitable, $39.4 \%$ was suitable, $46.7 \%$ was unsuitable for recreational purposes (Fig. 4, Table 6).

Natural landscape aesthetic is the desirable component for every encounter with the natural environment in tourism and recreation activities [40]. 
Table 4. Pair comparison matrix of each criteria.

\begin{tabular}{|c|c|c|c|c|c|c|c|c|c|c|}
\hline Evaluation criteria & $\mathrm{C} 1$ & $\mathrm{C} 2$ & $\mathrm{C} 3$ & $\mathrm{C} 4$ & $\mathrm{C} 5$ & $\mathrm{C} 6$ & $\mathrm{C} 7$ & $\mathrm{C} 8$ & $\mathrm{C} 9$ & $\mathrm{C} 10$ \\
\hline $\mathrm{C} 1$ & 1 & - & - & - & - & - & - & - & - & - \\
\hline $\mathrm{C} 2$ & 0.111 & 1 & - & - & - & - & - & - & - & - \\
\hline $\mathrm{C} 3$ & 0.125 & 0.111 & 1 & - & - & - & - & - & - & - \\
\hline $\mathrm{C} 4$ & 0.143 & 0.125 & 0.111 & 1 & - & - & - & - & - & - \\
\hline $\mathrm{C} 5$ & 0.167 & 0.143 & 0.125 & 0.111 & 1 & - & - & - & - & - \\
\hline $\mathrm{C} 6$ & 0.200 & 0.167 & 0.143 & 0.125 & 0.111 & 1 & - & - & - & - \\
\hline $\mathrm{C} 7$ & 0.25 & 0.200 & 0.167 & 0.143 & 0.125 & 0.111 & 1 & - & - & - \\
\hline $\mathrm{C} 8$ & 0.333 & 0.25 & 0.200 & 0.167 & 0.143 & 0.125 & 0.111 & 1 & - & - \\
\hline $\mathrm{C} 9$ & 0.500 & 0.333 & 0.250 & 0.200 & 0.167 & 0.143 & 0.125 & 0.111 & 1 & - \\
\hline $\mathrm{C} 10$ & 1.000 & 0.500 & 0.333 & 0.250 & 0.20 & 0.167 & 0.143 & 0.125 & 0.111 & 1 \\
\hline
\end{tabular}

Consistency ratio: 0.005

Table 5. Defined ranking and weight of landscape aesthetic assessment criteria.

\begin{tabular}{|c|c|c|}
\hline Criteria & Ranking & Weight \\
\hline Density of boundaries between visually identifiable natural features & F1 & 0.22341 \\
\hline Diversity of the constituent elements & F2 & 0.17745 \\
\hline Color palette & F3 & 0.14114 \\
\hline Composition nodes & F4 & 0.11180 \\
\hline Composition axes & F5 & 0.08820 \\
\hline Availability of scene sides & F6 & 0.05935 \\
\hline Depth and diversity of visual perspective & F7 & 0.04288 \\
\hline Forest coverage & F8 & 0.03451 \\
\hline Symbolic natural objects & F9 & 0.03074 \\
\hline
\end{tabular}

Visual elements of the landscape not only embody aesthetic values, but also verify the mutual relationships of these values in cultural, economic, traditional behavior, and biological dimensions [41]. The main feature of Mongolia's natural landscape is that it is low relatively unaffected by human impact. This is more suitable for assessing natural landscape aesthetics [42]. Landscape research in Mongolia focuses on the rational use and protection of natural resources.

Table 6. Results of landscape aesthetic assessment.

\begin{tabular}{|c|c|c|}
\hline \multirow{2}{*}{} & \multicolumn{2}{|c|}{ Total area } \\
\cline { 2 - 3 } & $\mathrm{km}^{2}$ & $\%$ \\
\hline Unsuitable (Low) & $32,516.5$ & 46.7 \\
\hline Suitable (Moderate) & $27,444.4$ & 39.4 \\
\hline Highly suitable (High) & $9,198.3$ & 13.2 \\
\hline
\end{tabular}

The results of the landscape mapping are of practical importance for the planning of the region, the proper use and planning of natural conditions and resources, and the determination of the carrying capacity of natural tourism [43]. Based on the specifics of the territory of Uvs Province, Mongolia, we conducted a landscape aesthetic assessment and mapped it, which is a model study.

The assessment of the landscape aesthetic at the local level is more specific to the results of the study [44]. This study differs from other studies, in that it covers the territory of Uvs province in the northwestern part of Mongolia, and determines the landscape capacity by hierarchical ranking based on many types of landscape. Using our research methodology, it is possible to determine the potential of the natural landscape, and determine the tourism and recreation resources based on it. 


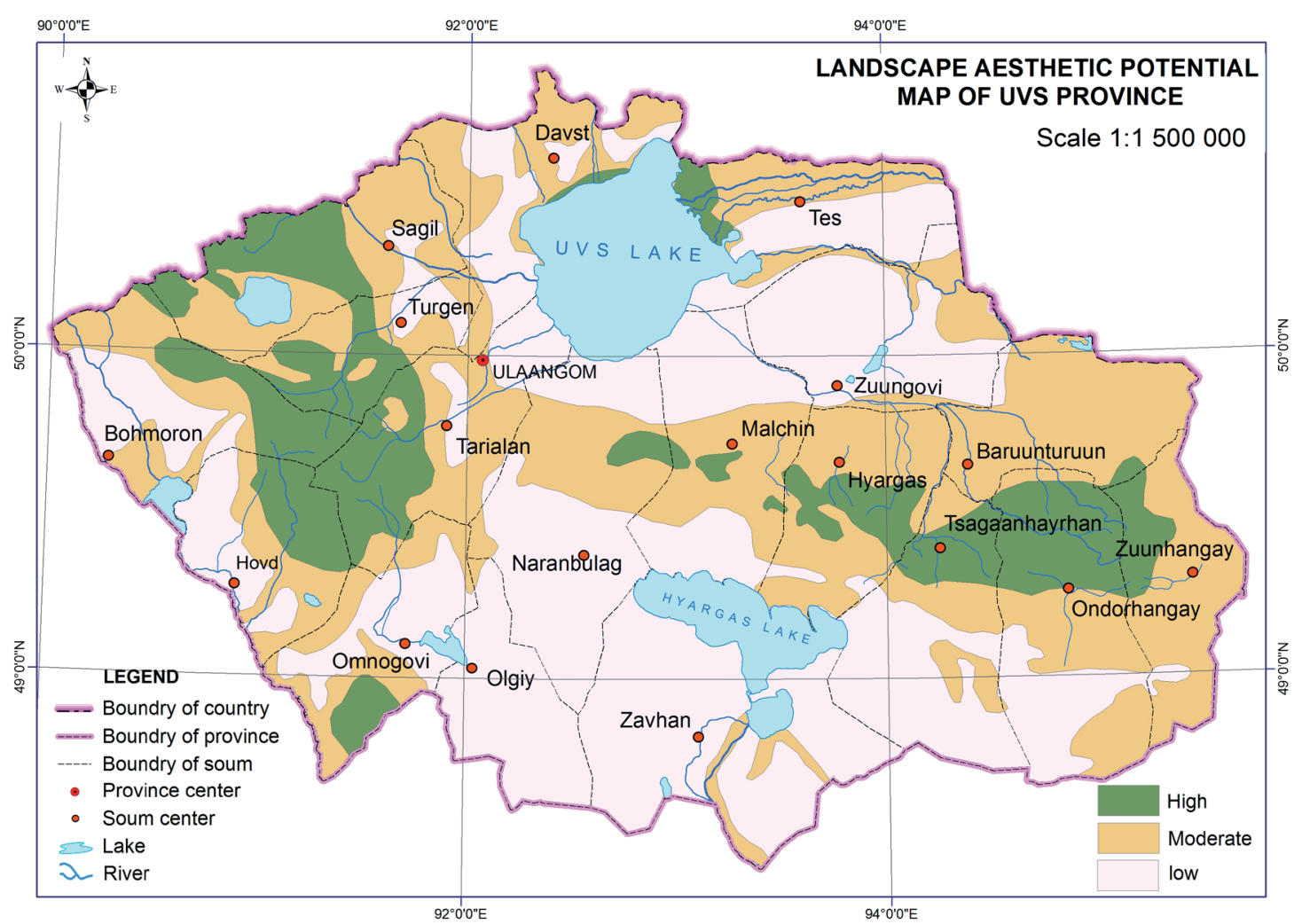

Fig. 4. Spatial distribution map of landscape aesthetic potential in Uvs province of Mongolia.

\section{Conclusions}

The natural landscape aesthetic of Uvs province, Mongolia, was assessed by ten criteria using a combination of spatial MCDM and AHP based on Boolean and Fuzzy logic. It was found that $13.2 \%$ of the area of Uvs province was highly suitable, $39.4 \%$ was suitable, and $46.7 \%$ was unsuitable for recreational purposes. This data served to compile the landscape aesthetic potential map of Uvs province at a spatial resolution of $10 \mathrm{~km}$.

The study confirmed that landscape aesthetic assessment for recreational purposes is possible using GIS and remote sensing technology based on a combination of the multi-criteria decision output and the matrix. The work will be continued to assess and map other regions of Mongolia. The obtained results can be used in land management.

The landscape aesthetic and scenery are the main factors in assessing natural conditions from the recreational point of view, and it is a new field of research in recreational geography that can suggest many other indicators for the stated purpose. The landscape aesthetic and scenery vary greatly in regions, districts and localities of Mongolia depending on their location, latitude, terrain combinations, and hence it is required to develop a system of criteria suitable to assess them.

This research tested the assessment criteria that was proposed by Dirin [33] previously used to assess landscapes in Ust-Koksinsky District of the Altai Republic, Russia. Future work will concentrate on exploring each of the criteria of landscape aesthetic to fully comprehend their meaning and content, to reform the measurement scales, to assess the pillar points, to compare the assessment of researchers with that of tourists, and to conduct surveys.

\section{Acknowledgements}

We thank all colleagues at the School of Natural Sciences and Technology, Khovd State University, and the Institute of Geography and Geoecology, Mongolian Academy of Sciences, who helped with this study.

\section{Conflict of Interest}

The authors declare no conflict of interest.

\section{References}

1. PASHER J., MITCHELL S.W., KING D.J., FAHRIG L., SMITH A.C., LINDSAY K.E. Optimizing landscape selection for estimating relative effects of landscape variables on ecological responses. Landscape Ecology. 28, 371, 2013.

2. POLAT A.T., AKAY A. Relationships between the visual preferences of urban recreation area users and various 
landscape design elements. Urban Forestry \& Urban Greening. 14, 573, 2015.

3. MUELLER L., EULENSTEIN F., MIRSCHEL W., ANTROP M., JONES M., MCKENZIE B.M., DRONIN N.M., KAZAKOV L.K., KRAVCHENKO V.V., KHOROSHEV A.V. Their Exploration and Utilisation: Status and Trends of Landscape Research. In Current Trends in Landscape Research. Springer: 105, 164. 2019.

4. WU J. Landscape sustainability science: ecosystem services and human well-being in changing landscapes. Landscape Ecology. 28, 999, 2013.

5. DOHERTY G., WALDHEIM C., Is landscape...? Essays on the identity of landscape. Routledge, 2015.

6. GYIMÓTHY S., DREDGE D. Definitions and Mapping the Landscape in the Collaborative Economy. In Collaborative Economy and Tourism: Perspectives, Politics, Policies and Prospects, Dredge D., Gyimóthy S., Eds. Springer International Publishing, Cham, 2017.

7. SANJMYATAB Z. Landscape Studies. Ulaanbaatar, Mongolia, pp. 29, 31, 2011.

8. DASH D. Landscape-ecological issues of Mongolia. Ulaanbaatar, Mongolia, pp. 53, 59, 2015.

9. VALE T., Fire, native peoples, and the natural landscape. Island Press, 2013.

10. GERMAIN R.M., STRAUSS S.Y., GILBERT B. Experimental dispersal reveals characteristic scales of biodiversity in a natural landscape. Proceedings of the National Academy of Sciences, 2017.

11. SMITH M., RAM Y. Tourism, landscapes and cultural ecosystem services: a new research tool. Tourism Recreation Research. 42, 113, 2017.

12. LENZEN M., SUN Y.Y., FATURAY F., TING Y.P., GESCHKE A., MALIK A. The carbon footprint of global tourism. Nature Climate Change. 8, 522, 2018.

13. BAYONA L.L., RUA A.R. The importance of online payment on Travel and Tourism incomes-A Cross-Country Panel Data Study. Academicus, 199, 2019.

14. FRANCH-PARDO I., NAPOLETANO B., BOCCO G., BARRASA S. CANCER-POMAR L. The role of geographical landscape studies for sustainable territorial planning. Sustainability. 2017.

15. KÜHNE O. Landscape and power in geographical space as a social-aesthetic construct. Springer. 2018.

16. JIANG P., LI M., LV J. The causes of farmland landscape structural changes in different geographical environments. Science of The Total Environment. 685, 667, 2019.

17. DORJSUREN B., YAN D., WANG H., CHONOKHUU S., ENKHBOLD A., DAVAASUREN D. GIRMA A., ABIYU A., JING L., GEDEFAW M., Observed trends of climate and land cover changes in Lake Baikal basin. Environmental Earth Sciences. 77, 725, 2018.18.

18. DORJSUREN B., YAN D., WANG H., CHONOKHUU S., ENKHBOLD A., YIRAN X., GIRMA A., GEDEFAW M., ABIYU A. Observed Trends of Climate and River Discharge in Mongolia's Selenga Sub-Basin of the Lake Baikal Basin. Water. 10, 1436, 2018.

19. TSEGMID S. Physical geography of Mongolia. Ulaanbaatar, Mongolia, 1969.

20. LEE-HSUEH L. Ecological Aesthetics: Design Thinking to Landscape Beauty with Healthy Ecology. In Landscape Architecture-The Sense of Places. Models and Applications. Intech Open, 2018.

21. CORTINOVIS C., ZULIAN G., GENELETTI D. Assessing Nature-Based Recreation to Support Urban Green Infrastructure Planning in Trento (Italy). Land. 7, 112, 2018.
22. ERDENEJARGAL N., CHOIJINJAV L., DOLJIN D. Assessing of natural landscape aesthetic uvs province of mongolia. Revista TURISMO. Estudos e Práticas, 2020.

23. KAPPAS M., DEGENER J., KLINGE M., VITKOVSKAYA I., BATYRBAYEVA M. A. Conceptual Framework for Ecosystem Stewardship Based on Landscape Dynamics: Case Studies from Kazakhstan and Mongolia. In Landscape Dynamics of Drylands across Greater Central Asia: People, Societies and Ecosystems, Gutman, G., Chen, J., Henebry, G.M., Kappas, M., Eds. Springer International Publishing: Cham, 143, 2020.

24. OTGONBAYAR M., ATZBERGER C., CHAMBERS J., AMARSAIKHAN D., BÖCK S., TSOGTBAYAR J. Land suitability evaluation for agricultural cropland in Mongolia using the spatial MCDM method and AHP based GIS. Journal of Geoscience and Environment Protection. 5, 238, 2017.

25. RONALD E.J., WEI-GEN J., PETER A. Raster procedures for multi-criteria/multi-objective decisions. Photogrammetric Engineering and Remote Sensing. 61, 539, 1995.

26. CEBALLOS-SILVA A., LÓPEZ-BLANCO J. Delineation of suitable areas for crops using a Multi-Criteria Evaluation approach and land use/cover mapping: a case study in Central Mexico. Agricultural Systems. 77, 117, 2003.

27. LIGMANN-ZIELINSKA A. Spatially-explicit sensitivity analysis of an agent-based model of land use change. International Journal of Geographical Information Science. 27, 1764, 2013.

28. DIN G.Y., YUNUSOVA A.B. Using AHP for evaluation of criteria for agro-industrial projects. International Journal of Horticulture and Agriculture. 1, 6, 2016.

29. WIJENAYAKE W.M., AMARASINGHE U.S., DE SILVA S.S. Application of a multiple-criteria decision making approach for selecting non-perennial reservoirs for culture-based fishery development: Case study from Sri Lanka. Aquaculture. 459, 26, 2016.

30. QURESHI M.R.N., SINGH R.K., HASAN M.A. Decision support model to select crop pattern for sustainable agricultural practices using fuzzy MCDM. Environment, Development and Sustainability. 20, 641, 2018.

31. KANDEL A. The Analytic Hierarchy Process-Planning, Priority Setting, Resource Allocation, Thomas L. Saaty (Ed.), McGraw-Hill, Basel (1980), p. 287. North-Holland: 1983.

32. SAATY T.L. Decision making with the analytic hierarchy process. International journal of services sciences. 1, 83, 2008.

33. DIRIN D.A. Aesthetic Landscape Resources of Mountainous Territories: Assessment, Rational Use and Protection (Example of the Ust-Koksinsky District of the Altai Republic). Barnaul, Alphabet, 260, 2005.

34. ERINGIS K., BUDRYUNAS A. The essence and method for the detailed ecological and aesthetic study of the landscapes. Ekologiya i estetika landshafta. 107, 1975.

35. DASH D. Landscape ecological issues of Mongolia. Ulaanbaatar, Mongolia, 135, 2010.

36. RA J.H., LEE Y.E., CHO H.J., KU J.N., KWON O.S Development and application of landscape diversity evaluation model on the basis of rural and natural area. Journal of the Korean Institute of Landscape Architecture. 41, 84, 2013.

37. SCHULZ C., KOCH R., CIERJACKS A., KLEINSCHMIT B. Land change and loss of landscape diversity at the Caatinga phytogeographical domain - Analysis of pattern- 
process relationships with MODIS land cover products (2001-2012). Journal of Arid Environments. 136, 54, 2017.

38. JIGJ S. The nature of reliefs in Mongolia. Ulaanbaatar, Mongolia, 1975.

39. TSEGMID S. Mongolian physics and geography. Ulaanbaatar, Mongolia, 1969.

40. SAEIDI S., MOHAMMADZADEH M., SALMANMAHINY A., MIRKARIMI S.H. Performance evaluation of multiple methods for landscape aesthetic suitability mapping: A comparative study between MultiCriteria Evaluation, Logistic Regression and Multi-Layer Perceptron neural network. Land Use Policy. 67, 1, 2017.

41. ANGILERI V., TOCCOLINI A. The assessment of visual quality as a tool for the conservation of rural landscape diversity. Landscape and Urban Planning. 24, 105, 1993.
42. STERNBERG T. Environmental challenges in Mongolia's dryland pastoral landscape. Journal of Arid Environments. 72, 1294, 2008.

43. MUNKHDULAM O., AVIRMED E., JONATHAN CH., RENCHINMYADAG T. Assessment of landscapeecological potential of Khovd province, Mongolia using satellite imagery and the spatial multicriteria decisionmaking method. Globa Scientific Journals. GSJ: Volume 6, 2018.

44. JAHANI A. Forest landscape aesthetic quality model (FLAQM): a comparative study on landscape modelling using regression analysis and artificial neural networks. Journal of Forest Science. 65, 61, 2019. 
